\section{Octreotide and Graves' ophthalmopathy and pretibial myxoedema}

\section{T C Chang, S C S Kao, K M Huang}

Departments of Internal Medicine, Ophthalmology, and Radiology, National Taiwan University Hospital, Taipei, Taiwan, Republic of China $\mathrm{T}$ C Chang, MD, professor of internal medicine

S C S Kao, MD, assistant professor of ophthalmology $\mathrm{K} M$ Huang, MD, associate professor of radiology

Correspondence to: Professor Chang.

BMF 1992;304: 158 myxoedema.
Existing treatments for severe Graves' ophthalmopathy such as immunosuppressive agents, orbital irradiation, and decompression are not fully satisfactory. The extraocular muscles and fat cells show immunoreactivity to insulin-like growth factor-1 (IGF-1), ${ }^{1}$ and this factor is also implicated in the pathogenesis of pretibial myxoedema. ${ }^{2}$ Octreotide, a potent long acting somatostatin analogue, ${ }^{3}$ suppresses IGF-1 activity either indirectly, by reducing plasma concentrations of growth hormone or directly, by blocking the effect of IGF-1 on peripheral tissue. ${ }^{4}$ We report the therapeutic effect of octreotide in six patients with Graves' ophthalmopathy, three of whom also had pretibial

\section{Case reports}

Case 1-A 27 year old woman with thyrotoxicosis had been treated with methimazole. She developed progressive exophthalmos, diplopia, and sore eyes, with epiphora. Octreotide $100 \mu \mathrm{g}$ thrice daily controlled the epiphora after two days and soreness after a week. Her diplopia began to improve after three weeks. Her condition remained stable after three months' treatment (table) and four months' follow up.

Case 2-A 58 year old woman with Graves' opthalmopathy and pretibial myxoedema was treated with octreotide $100 \mu \mathrm{g}$ thrice daily. Her symptoms, including the myxoedema resolved after four weeks, and she remained well three months after taking octreotide for three months (table).

Case 3-A 37 year old man developed worsening exophthalmos and diplopia in all directions of gaze after a thyroidectomy. He took octreotide $100 \mu \mathrm{g}$ thrice daily for three months with some improvement in his diplopia on right gaze (table). No change was observed after follow up for two months.

Case 4-A 50 year old woman previously treated by thyroidectomy and radioactive iodine developed pre- tibial myxoedema, exophthalmos, and excessive lacrimation. Octreotide $100 \mu \mathrm{g}$ thrice daily controlled the lacrimation after four days and the erythema of her pretibial skin after six. After three months' treatment her eye movements and skin changes had almost fully returned to normal (table). She remained stable six weeks after stopping treatment.

Case 5-A 62 year old man with exophthalmos and diplopia in all directions of gaze improved on octreotide $100 \mu \mathrm{g}$ thrice daily for three months (table) and remained stable six weeks after stopping treatment.

Case 6-A 43 year old woman with Graves' disease for 20 years developed progressive exophthalmos and pretibial myxoedema after a thyroidectomy. Three months' treatment with octreotide $100 \mu \mathrm{g}$ thrice daily reduced her exopthalmos (table) and her skin changes. She remained stable one month after stopping treatment.

\section{Comment}

Octreotide may inhibit local synthesis of IGF-1 from inflammation or through postreceptor inhibition ${ }^{4}$ and thereby inhibit glycosaminoglycan synthesis by fibroblasts in the orbit and skin. Control of epiphora is probably related to inhibition of exocrine secretion whereas rapid improvement in itching and erythema may indicate inhibition of release of inflammatory mediators. Our experience suggests that octreotide treatment is effective in Graves' ophthalmopathy and pretibial myxoedema and is associated with minor side effects: mild abdominal discomfort in the first week of treatment and pain at the injection site. Additional studies are required to ascertain the exact mechanism of action of octreotide.

We thank Sandoz Pharmaceuticals for supplying the octreotide, and Dr R Teoh for his help.

1 Hansson H-A, Petruson B, Skottner A. Somatomedin C in pathogenesis of malignant exophthalmos of endocrine origin. Lancet 1986;i:218-9.

2 Kriss JP. Pathogenesis and treatment of pretibial myxedema. Endocrinol Metab Clin North Am 1987;16:409-15.

3 Bauer W, Briner U, Doepfner W, Haller R, Huguenin R, Marbach P, et al. SMS 201-995: a very potent and selective octapeptide analogue of somatostatin with prolonged action. Life Sci 1982;31:1133-40.

4 Tsuzaki S, Moses AC. Somatostatin inhibits deoxyribonucleic acid synthesis induced by both thyrotropin and insulin-like growth factor-I in FRTL-5 cells . Endocrinology 1990;126:3131-8.

(Accepted 30 fuly 1991)

Ophthalmic data before and after treatment with octreotide for three months

\begin{tabular}{|c|c|c|c|c|c|c|c|c|c|}
\hline \multirow{2}{*}{$\begin{array}{l}\text { Case } \\
\text { No }\end{array}$} & \multirow{2}{*}{$\begin{array}{l}\text { Affected } \\
\text { side }\end{array}$} & \multicolumn{2}{|c|}{ Visual acuity } & \multicolumn{2}{|c|}{ Exophthalmos (mm) } & \multicolumn{2}{|c|}{$\begin{array}{l}\text { Degree of limitation of } \\
\text { upward gaze }\end{array}$} & \multicolumn{2}{|c|}{$\begin{array}{l}\text { Major changes on computed tomography } \\
\text { (enlarged extraocular muscles or increased orbital fat) }\end{array}$} \\
\hline & & Before & After & Before & After & Before & After & Before & After \\
\hline \multirow[t]{2}{*}{1} & Right & $20 / 30$ & $20 / 20$ & $18 \cdot 0$ & $17 \cdot 0$ & 3 & 2 & Inferior, medial rectus muscles & Inferior, medial rectus muscles \\
\hline & Left & $20 / 20$ & $20 / 20$ & $19 \cdot 5$ & $19 \cdot 0$ & 0 & 0 & Superior, medial rectus muscles & Superior, medial rectus muscles $\dagger$ \\
\hline \multirow[t]{2}{*}{2} & Right & $20 / 30$ & $20 / 25$ & $18 \cdot 0$ & $17 \cdot 0$ & 2 & 2 & Superior, medial rectus muscles & Superior, medial rectus muscles \\
\hline & Left & $20 / 20$ & $20 / 20$ & $18 \cdot 0$ & $17 \cdot 5$ & 2 & 2 & Superior, medial rectus muscles & Superior, medial rectus muscles \\
\hline \multirow[t]{2}{*}{3} & Right & $20 / 18$ & $20 / 18$ & $21 \cdot 0$ & $19 \cdot 0$ & 0 & 0 & Superior, inferior, medial rectus muscles & Superior, inferior, medial rectus muscles \\
\hline & Left & $20 / 18$ & $20 / 18$ & $24 \cdot 0$ & $22 \cdot 5$ & 1 & 1 & Superior, inferior, medial rectus muscles & Superior, inferior, medial rectus muscles \\
\hline \multirow[t]{2}{*}{4} & Right & $20 / 30$ & $20 / 25$ & $20 \cdot 0$ & $18 \cdot 5$ & 3 & 1 & Superior, inferior, medial rectus muscles & ND \\
\hline & Left & $20 / 30$ & $20 / 25$ & $21 \cdot 0$ & $21 \cdot 0$ & 3 & 1 & Superior, inferior, medial rectus muscles & 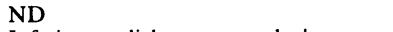 \\
\hline \multirow[t]{2}{*}{5} & Right & $20 / 25$ & $20 / 25$ & $22 \cdot 0$ & $19 \cdot 0$ & 1 & 1 & Inferior, medial rectus muscles & Inferior, medial rectus muscles $\dagger$ \\
\hline & Left & $20 / 25$ & $20 / 20$ & $24 \cdot 0$ & $21 \cdot 0$ & 3 & 2 & Inferior, medial rectus muscles & Inferior, $\nmid$ medial rectus muscles \\
\hline \multirow[t]{2}{*}{6} & Right & $20 / 25$ & $20 / 25$ & $23 \cdot 0$ & $20 \cdot 5$ & 0 & 0 & Fat & ND \\
\hline & Left & $20 / 20$ & $20 / 20$ & $25 \cdot 0$ & 22.5 & 0 & 0 & Fat & ND \\
\hline
\end{tabular}

*Degree of limitation: $0=$ no limitation, $1=$ mild limitation, $2=$ moderate limitation, $3=$ severe limitation.

†Decrease in muscle thickness.

$\mathrm{ND}=$ not done 